\title{
Effect of Different Acids on the Scale in Pipelines of Linz-Donawitz (LD) Plant (Steel Making Process)
}

\author{
Swastic ${ }^{1}$, Suprotim Das ${ }^{2}$ \\ ${ }^{1}$ Chemical Engineering, Bits-Pilani KK Birla Goa Campus, Zuarinagar, India \\ ${ }^{2}$ TATA Steel, Jamshedpur, India \\ Email: swastic.singh@gmail.com, suprotim.das@tatasteel.com
}

Received 1 January 2015; accepted 6 April 2015; published 10 April 2015

Copyright (C 2015 by authors and Scientific Research Publishing Inc.

This work is licensed under the Creative Commons Attribution International License (CC BY). http://creativecommons.org/licenses/by/4.0/

(c) (i) Open Access

\begin{abstract}
In this report we present the effect of different acids on the scales taken from LD plant. The main aspect of the problem is to find a suitable concentration and type of acid to reduce/remove the deposition of scale in the pipeline. The analysis is carried out using a combination of suggestions dictated by experimental evidence and suitable mathematical techniques. Result reveals that $5 \%$ solution of Hydrochloric Acid is most effective to dissolve the scale in a specified time at room temperature. The order of effectiveness to dissolve the scale deposits is $\mathrm{HCL}>\mathrm{HNO}_{3}>\mathrm{H}_{3} \mathrm{NSO}_{3}>$ $\mathrm{H}_{2} \mathrm{C}_{2} \mathrm{O}_{4}>\mathrm{H}_{2} \mathrm{SO}_{4}$. But when it comes to the corrosion in the pipe the order of corrosion caused by acids is $\mathrm{HCL}>\mathrm{H}_{3} \mathrm{NSO}_{3}>\mathrm{HNO}_{3}$. So, when we consider both the results $\mathrm{HNO}_{3}$ is the most suitable acid with respect to both scale deposition and corrosion of the pipelines. Predictions of the data are compared with experiments finding a remarkable agreement with the available data.
\end{abstract}

\section{Keywords}

Scales, LD Plant, Acids

\section{Introduction}

Excessive scale formation in the water pipeline can cause interruption in water supply and serious abrasion of pumps with consequent high operating costs.

Scale formation is the most common problem faced today by any steel plant. The reason for this is the presence of different ions in the water that cause the formation of scales in the pipelines and when we narrow down to ld process in any steel plant then we find that the water used to strip the gases coming out of the ld plant con- 
tains total suspended solids (TSS) and total dissolved solids (TDS). By using different technics, TSS and TDS are removed from the water but the presence of some amount of calcium and magnesium in wastewater is causing scale formation in the pipelines and if we don't remove scales at a regular interval of time it will lead to clogging of pipeline. And also the presences of small amount of calcium and magnesium ions make it undesirable for reuse in any process in any industry [1] [2]. So it is needed to remove the sediments from the pipeline at a regular interval either by chemical methods or physical methods.

To effectively prevent scale deposits, a number of factors should be considered, such as flow rate of the solutions [3] [4], temperature [5] and use of antiscaling agents [6] [7]. There were different methods for the removal and prevention of scaling in the pipeline like filtration, aeration etc. At present methods like plain settling, aeration ( $\mathrm{CO}_{2}$ purging), coagulation and flocculation are being implemented in several industries. But the scale deposition problem is still there. So, acid is more preferable to remove scales in the present scenario at LD. But the question is how much and which acid we can use?

\section{Materials and Methods}

\subsection{Materials}

$1 \%, 2 \%, 3 \%, 4 \%$ and $5 \%$ concentrations of Hydrochloric acid ( $\mathrm{HCl})$, Sulphuric acid $\left(\mathrm{H}_{2} \mathrm{SO}_{4}\right)$, Nitric acid $\left(\mathrm{HNO}_{3}\right)$, Oxalic acid $\left(\mathrm{H}_{2} \mathrm{C}_{2} \mathrm{O}_{4}\right)$ and Sulfamic acid $\left(\mathrm{H}_{3} \mathrm{NSO}_{3}\right)$ were used.

\subsection{Methods}

\subsubsection{Dissolution of Scales in Acids}

$5 \mathrm{gm}$ of scale (from LD of Steel plant) was taken. Certain volume of acid was taken with different concentration (1\%, 2\%, 3\%, 4\% and 5\%) of acid each time. Content was kept for 60 mins at room temperature. Then it was filtered using filter paper, dried by air blow drier and weighted.

\subsubsection{Corrosion in Pipe Due to Different Acids}

$5 \%$ solution of $\mathrm{HCl}, \mathrm{NO}_{3}$ and $\mathrm{H}_{3} \mathrm{NSO}_{3}$ were prepared. A piece of pipe was dipped in each acid for 60 mins. The piece of pipe was weighted and the difference in weight was calculated.

\section{Results and Discussion}

$\mathrm{HCl}$ can remove most of the scales (Table 1) but there is a possibility that it will corrode the pipe as well. Apart from corrosion $\mathrm{HCl}$ also cannot be used in pipes made up of stainless steel since the protective chromiumoxide layer on stainless steel is corroded by the halide. Nitric acid can also dissolve scales but less than HCl (Table 2). Also nitric acid can be used in pipes made up of stainless steel since it is an oxidising acid hence it increases the chromium oxide layer (Figure 1). Sulphuric acids cannot be used to remove scale since it forms precipitate (Table 3). Oxalic acid, at low concentration dissolves small amount of scale but at concentration more than 2\% it forms precipitate (Table 4). Sulfamic acid, its 5\% dissolves around 30\% of the scale (Table 5). The comparison done in Figure 2 gives us a fair amount of knowledge about the action of different acid on scale. From this experiment we came to know that we have only 3 acids but there is a chance of corrosion of pipeline from those acids so we did one more experiment to see the corrosion in the pipe from different acids.

From Table 6, corrosion would be most due to hydrochloric acid than it's due to sulphamic acid and it would be least due to nitric acid.

Table 1. Effect of concentration of $\mathrm{HCl}$ on scale.

\begin{tabular}{cccccc}
\hline Concentration & Time & Initial Weight & Final Weight & Weight Dissolved & \% Weight Dissolved \\
\hline$\%$ & min & gm & gm & gm & gm \\
\hline 1 & 60 & 5 & 4.1362 & 0.8630 & 17.276 \\
2 & 60 & 5 & 3.808 & 2.192 & 43.84 \\
3 & 60 & 5 & 2.8317 & 2.1683 & 62.69 \\
4 & 60 & 5 & 1.8655 & 3.1345 & 8.1544 \\
\hline
\end{tabular}




$$
\begin{aligned}
& 1 \frac{1}{2} \mathrm{Cu}+4 \mathrm{H}^{+}+\mathrm{NO}_{3}^{-} \rightarrow 1 \frac{1}{2} \mathrm{Cu}^{2+}+\mathrm{NO}(\mathrm{g})+2 \mathrm{H}_{2} \mathrm{O} \\
& \text { (or } \mathrm{Fe}) \quad\left(\text { or } \mathrm{Fe}^{3+}\right. \text { ) } \\
& \text { air } \\
& \mathrm{NO}_{2} \text { (brown toxic gas) }
\end{aligned}
$$

Figure 1. Shows oxidising nature of nitric acid.

Table 2. Effect of concentration of $\mathrm{H}_{2} \mathrm{SO}_{4}$ on scale.

\begin{tabular}{cccccc}
\hline Concentration & Time & Initial Weight & Final Weight & Weight of precipitate & \% Weight of Precipitate \\
\hline$\%$ & min & gm & gm & gm & gm \\
\hline 1 & 60 & 5 & 5.442 & 0.442 & 8.8407 \\
2 & 60 & 5 & 6.1974 & 1.1974 & 23.9473 \\
3 & 60 & 5 & 6.608 & 1.608 & 32.1613 \\
4 & 60 & 5 & 6.9179 & 1.9179 & 38.3591 \\
5 & 60 & 5 & 6.8879 & 1.8879 & 37.7596 \\
\hline
\end{tabular}

Table 3. Effect of concentration of $\mathrm{HNO}_{3}$ on scale.

\begin{tabular}{cccccc}
\hline Concentration & Time & Initial Weight & Final Weight & Weight Dissolved & \%Weight Dissolved \\
\hline$\%$ & min & gm & gm & gm & gm \\
\hline 1 & 60 & 5 & 4.1562 & 0.8438 & 16.8763 \\
2 & 60 & 5 & 3.8201 & 1.1799 & 23.5985 \\
3 & 60 & 5 & 3.0445 & 1.9555 & 39.1106 \\
4 & 60 & 5 & 2.0126 & 2.9874 & 59.7491 \\
5 & 60 & 5 & 1.6965 & 3.3035 & 66.0702 \\
\hline
\end{tabular}

\begin{tabular}{|c|c|c|c|c|c|}
\hline Concentration & Time & Initial Weight & Final Weight & Weight Dissolved & \%Weight Dissolved \\
\hline$\%$ & $\min$ & gm & gm & gm & gm \\
\hline 1 & 60 & 5 & 4.9585 & 0.03102 & 0.6204 \\
\hline 2 & 60 & 5 & 4.3988 & 0.44938 & 8.9876 \\
\hline 3 & 60 & 5 & 3.9621 & 0.7758 & 15.516 \\
\hline 4 & 60 & 5 & 3.9373 & 0.7943 & 15.8868 \\
\hline 5 & 60 & 5 & 3.0584 & 1.4629 & 29.259 \\
\hline
\end{tabular}

Table 4. Effect of concentration of $\mathrm{H}_{2} \mathrm{C}_{2} \mathrm{O}_{4}$ on scale.

\begin{tabular}{cccccc}
\hline Concentration & Time & Initial Weight & Final Weight & Weight of Precipitate & \% Weight of Precipitate \\
\hline$\%$ & min & gm & gm & gm & gm \\
\hline 1 & 60 & 5 & 4.947 & -0.0872 & -1.743 \\
2 & 60 & 5 & 4.991 & -0.0148 & -0.296 \\
3 & 60 & 5 & 5.0034 & 0.00559 & 0.1118 \\
4 & 60 & 5 & 5.0278 & 0.04572 & 0.9143 \\
5 & 60 & 5 & 5.0539 & 0.08863 & 1.7727 \\
\hline
\end{tabular}

Table 5. Effect of concentration of $\mathrm{H}_{3} \mathrm{NSO}_{3}$ on scale. 


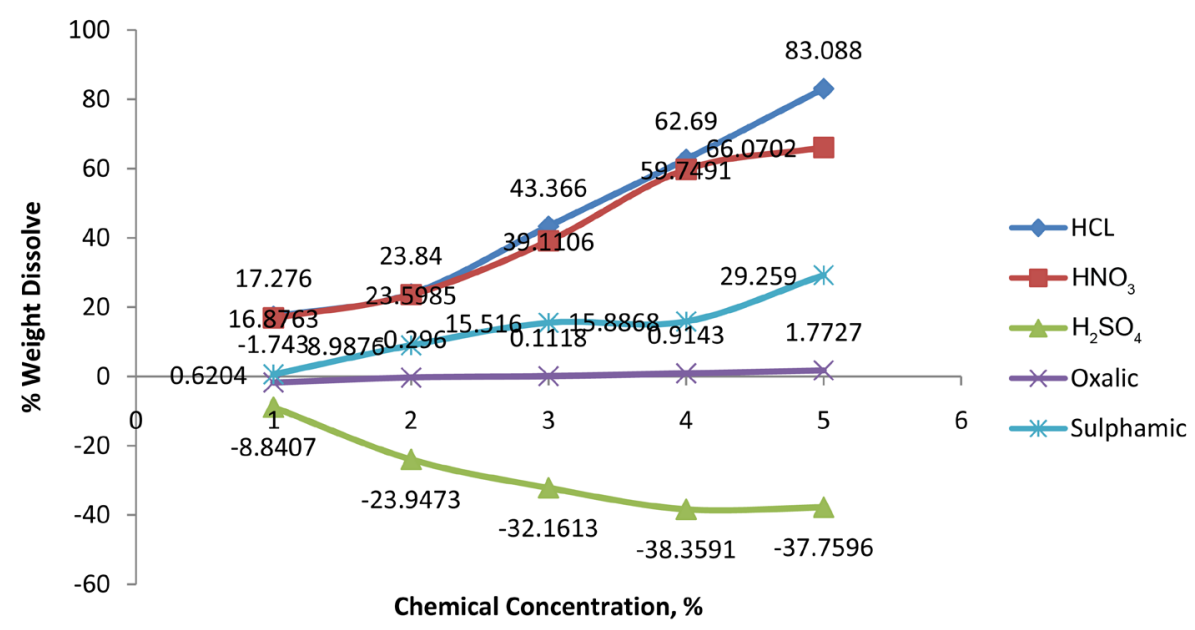

Figure 2. Percentage dissolved scale versus concentration.

Table 6. Effect of different acids on pipe.

\begin{tabular}{cccccc}
\hline Concentration \% & Time mins & Acid & Initial Weight gm & Final Weight gm & Weight Dissolved in Acid gm \\
\hline $5 \%$ & 60 & Hydrochloric & 788.7 & 781.8 & 6.9 \\
$5 \%$ & 60 & Nitric & 778.7 & 772.85 & 5.85 \\
$5 \%$ & 60 & Sulphamic & 797.7 & 791.7 & 6 \\
\hline
\end{tabular}

\section{Conclusion}

From experimental results with different acids (organic/inorganic) one concludes that inorganic acids work more efficiently than organic acids as we can see oxalic acid dissolves much less amount of scale than hydrochloric or nitric acid. It is evident that $\mathrm{HCl}$ works most efficiently when we only consider scale dissolution. But with the data from the experiment on corrosion we can see that $\mathrm{HCl}$ can also corrode the pipe and is not useful with pipes made of stainless steel. According to the experiments we get Nitric acid as the second best acid for dissolution of scales and when we consider corrosion as a factor, it will corrode least amongst all the acids being used. Apart from that we can also use nitric acid with stainless steel pipes.

\section{Acknowledgements}

The authors acknowledge the financial support as well as support through facilities provided by TATA Steel, Jamshedpur.

\section{References}

[1] Reddy, M.M. and Hoch, A.R. (2001) Calcite Crystal Growth Rate Inhibition by Polycarboxylic Acids. Journal of Colloid and Interface Science, 235, 365-370. http://dx.doi.org/10.1006/jcis.2000.7378

[2] Chong, H.T. and Sheikholeslami, R. (2001) Thermodynamics and Kinetics for Mixed Calcium Carbonate and Calcium Sulphate Precipitation. Chemical Engineering Science, 56, 5391-5400. http://dx.doi.org/10.1016/S0009-2509(01)00237-8

[3] Kirboga, S. and Oner, M. (2013) Effect of the Experimental Parameters on Calcium Carbonate Precipitation. Chemical Engineering Transactions, 32, 2119-2124. http://dx.doi.org/10.3303/CET1332354

[4] Muryanto, S., Bayuseno, A.P., Sediono, W., Mangestiyono, W. and Sutrisno (2012) Development of a Versatile Laboratory Project for Scale Formation and Control. Education for Chemical Engineers, 7, e78-e84. http://dx.doi.org/10.1016/j.ece.2012.04.002

[5] Hoang, T.A., Ang, H.M. and Rohl, A.L. (2007) Effects of Temperature on the Scaling of Calcium Sulphate in Pipes. Powder Technology, 179, 31-37. http://dx.doi.org/10.1016/j.powtec.2006.11.013 
[6] Greenlee, L.F., Testa, F., Lawler, D.F., Freeman, B.D. and Moulin, P. (2010) The Effect of Antiscalant Addition on Calcium Carbonate Precipitation for a Simplified Synthetic Brackish Water Reverse Osmosis Concentrate. Water Research, 44, 2957-2969. http://dx.doi.org/10.1016/j.watres.2010.02.024

[7] Tang, Y.M., Yang, W.Z., Yin, X.S., Liu, Y., Yin, P.W. and Wang, J.T. (2008) Investigation of $\mathrm{CaCO}_{3}$ Scale Inhibition by PAA, ATMP and PAPEMP. Desalination, 228, 55-60. http://dx.doi.org/10.1016/j.desal.2007.08.006

\section{Acronyms}

LD = Linz Donawitz

TSS $=$ Total Suspended Solids

TDS $=$ Total Dissolved Solids

GCP $=$ Gas Cleaning Plant 